\title{
Editor's Note: Special Issue on Application-specific Systems, Architectures and Processors
}

Published online: 5 August 2020

(C) Springer Science+Business Media, LLC, part of Springer Nature 2020

Journal of Signal Processing Systems gratefully acknowledges the editorial work of the scholar listed below on the special issue entitled "Application-specific Systems, Architectures and Processors."

Dr. Yun (Eric) Liang

Program Chair, ASAP 2019

Center for Energy-efficient Computing and Applications (CECA)
Dr. Zhenman Fang

Simon Fraser University

Dr. Jieming Yin

AMD Research

Dr. Cunxi Yun

The University of Utah

Publisher's Note Springer Nature remains neutral with regard to jurisdictional claims in published maps and institutional affiliations. 